\title{
Assessment of Knowledge, Attitudes, and Practice (KAP) Among Dentists toward Carpal Tunnel Syndrome in Shiraz, Iran.
}

Hamid Reza Farpour

Shiraz University of Medical Sciences

Aref Nasiri

Shiraz University of Medical Sciences

Alireza Sadighi

Shiraz University of Medical Sciences

Kayvon Seyed Dehghanian

Shiraz University of Medical Sciences

Faisal Ahmed ( $\nabla$ fmaaa2006@yahoo.com )

Al-Thora hospital, Ibb University of Medical Since

Mohammad Hossein Taghrir

Shiraz University of Medical Sciences

Ebrahim Al-shami

Al-Thora hospital, Ibb University of Medical Since

Khalil Al-naggar

Al-Thora hospital, Ibb University of Medical Since

\section{Research Article}

Keywords: Carpal Tunnel Syndrome, Dentist, Health Knowledge, Attitudes, Practice.

Posted Date: June 23rd, 2021

DOI: https://doi.org/10.21203/rs.3.rs-634947/v1

License: (1) (1) This work is licensed under a Creative Commons Attribution 4.0 International License. Read Full License 


\section{Abstract}

Background: Carpal tunnel syndrome (CTS) is a common work-place musculoskeletal disorder, and dentists are a high-risk group due to their work conditions. This study aims to obtaining a full understanding of knowledge, attitude and practice (KAP) of CTS among Dentists in Shiraz, Iran.

Methods: Between Jun,2019 and Dec,2019; A researcher-made questionnaire was developed for this cross-sectional pilot study in order to evaluate the KAP of dentists regarding CTS. Participants were recruited to fill out the questionnaire. The participants were recruited using convenient sampling from dentists working. A 51 dentists were completed the survey. Ethical approval to conduct this study was obtained.

Results: About 31 (60.8\%) respondents were female and 20(39.2\%) were male. 54.9\%. of the participants were aged below 33 years. $66.7 \%$. of dentists had less than 10 years of work experience. No statistically significant correlation was observed between age, and number of years of work experience and KAP scores. But there was significant correlation between gender and knowledge $(p=0.04)$. The mean scores of knowledges were $3.7 \pm 1.3$ which was low to average regarding the prevention and treatment of CTS. The mean scores of attitudes and practice were $10.9 \pm 3.2$ and $7.9 \pm 2.1$, respectively. Which represent a positive attitude and practice towards regarding the prevention and treatment of CTS. There was a significant correlation between attitude and practice among dentists with $p=0.001$

Conclusions: Most dentists in this study had low to average knowledge, high attitudes, and high practice scores of the prevention and treatment of CTS.

\section{Introduction}

Implementing proper workplace ergonomics creates a safe, productive, and comfortable working environment. Dental health workers have a demanding job that requires strenuous and repetitive movements and frequent use of vibratory tools. Unsuccessful application of ergonomics can lead to work-related musculoskeletal disorders (MSD); a term referring to MSD that are brought on or exacerbated by risk factors in the workplace. ${ }^{[1]}$ The hands are one of the most affected regions of the body. ${ }^{[2]}$ Carpal tunnel syndrome (CTS) is a common MSD of the hands and wrists. ${ }^{[1]}$ The median nerve along with tendons of nine of the flexor muscles of the digits pass through the space between the flexor retinaculum and the bones of the wrist. If this space, called the carpal tunnel, decreases in diameter or if there's swelling of the tissues inside this space, the median nerve can become trapped and cause the symptoms of CTS. ${ }^{[3]}$ It is believed that one in every five symptomatic patient has CTS based on clinical examinations and nerve conduction study. ${ }^{[4]}$ The overall prevalence based on physical examinations in the general population in Iran is estimated to be $17.5 \%$; therefore, CTS has a high prevalence in Iran. ${ }^{[5]}$ The most common symptoms include pain, paresthesia, and numbness in the first, second, and third digits along with the radial half of the fourth digit. ${ }^{[6]}$ Some patients also report unusual pain patterns including elbow pain, shoulder pain, and neck pain. ${ }^{[6]}$ Personal factors such as advanced age, female 
gender, a higher body mass index, and smoking are associated with a higher incidence of CTS.

${ }^{[7]}$ Occupational risk factors include bending and twisting of the hand, working with vibratory tools, and repetitive hand use. ${ }^{[8]}$

CTS occurs more frequently in patients with systemic illnesses such as hypothyroidism, diabetes mellitus, and rheumatoid arthritis. ${ }^{\left[{ }^{[0]}\right.}$ Diagnosis is made mainly by obtaining a thorough history of the patient and performing physical examinations such as the Phalen's and Tinel's tests. ${ }^{[10]}$

Electrodiagnosis is the gold standard for diagnosing and determining the severity of CTS. ${ }^{[11]}$ Treatment is based on disease severity. Mild to moderate cases can benefit from conservative management including splinting, laser therapy and local corticosteroid injections. ${ }^{[12]}$ However, a proportion of those treated conservatively and those with severe or recurrent symptoms will eventually require surgery. ${ }^{[13]}$ Recovery after carpal tunnel release surgery can take up to a year. ${ }^{[13]}$

There are more than 37,000 registered dentists in Iran. Of them, 1,800 are registered in Shiraz, Iran. ${ }^{[14]}$ Sixteen percent of dentists in Iran are diagnosed with CTS by physical examination; ${ }^{[14]}$ a significant burden considering the hours of lost productive work due to the lengthy treatment course of CTS. It is crucial to prevent, rather than treat, CTS. The more informed the dentists are regarding CTS, the more likely they are to have positive attitudes toward modifying risk factors and practicing healthier behaviors in their workplace.

The aim of this paper was to lay a foundation for a future larger study to assess the knowledge, attitudes, and practice (KAP) of dentists practicing in a populous city in south of Iran regarding CTS. No similar study has been conducted so far. Hopefully, the results of the future main study will guide policymakers to take measures to decrease the burden of CTS on our healthcare workers.

\section{Materials \& Methods}

\section{Study design:}

This cross-sectional pilot study was designed to assess the knowledge, attitudes, and practice (KAP) toward CTS among dentists working in Shiraz, Iran from January to December 2019. A researcher-made questionnaire was developed for this study. The university's Deputy of Health department provided a list of all medical facilities. By relying on a similar study and choosing a confidence level of $95 \%$, ninety-one samples were recruited by non-randomized convenient sampling from public and private health sectors. Practicing in Shiraz, Iran, and a minimum of three years of work experience were considered as the inclusion criteria. Lack of consent was determined as the criterion of exclusion.

Two members of the research team held a Bachelor of Science in health information technologies and were oriented by the research team and directed to the hospitals to collect data. Data were collected using a demographic form and a research survey. 
The questionnaire consisted of 5 parts.

1. Demographics including age, sex, and work experience.

2. Medical history such as history of wrist pain, numbness and paresthesia in hands, rheumatic diseases, and endocrine diseases.

3. Knowledge which included 12 multiple-choice questions.

4. Attitudes which included 15 multiple-choice questions.

5. Practice which included 12 multiple-choice questions.

The respondent was offered multiple choices on each question. Each correct response had a score of 1 and any incorrect responses yielded a score of zero. Hence, the possible attainable knowledge scores ranged from zero to 12 , the attitudes from zero to 15 , and the practice from zero to 12 . A semi-structured self-administered questionnaire was used as the study instrument. The questionnaire was adapted from pre-existing templates. ${ }^{[15,16]}$

The face and content validity of the questionnaire was determined by surveying a group of physical medicine and rehabilitation attending physicians. A 4-point Likert scale was used to rate the validity of each item of the questionnaire. The survey inquired about the equivocalness, clarity, simplicity, and relevance of each item to determine the content validity of the questionnaire. For face validity, the survey probed 3 inquires: the likeliness that the respondent would be able to answer the question, the clarity of the choice of words, and the overall style and layout of questionnaire. The test-rest reliability was confirmed by ten subjects from the sample population. The reliability of this questionnaire was also assessed by the Cronbach's alpha coefficient $(a=0.8)$.

Two age groups were defined using the median of the respondents' ages. The median of age was 33 years. The respondents were divided into 3 groups based on their years of work experience: those with $<10$ years, those with 10-20 years, and those with $>20$ years of work experience.

To objectively compare the results of the study with similar studies, the KAP scores were divided into three groups using the tertials of the scores of each section as the cutoff. Thus, for the knowledge and practice section, scores $\leq 3$ were considered low, $\geq 8$ high, and 4-7 average. For the attitudes section, scores $\leq 4$ were considered low, $\geq 10$ high, and $5-9$ average.

The study was approved by the ethics committee. Written informed consent was obtained from each participant before filling out the questionnaire. The questionnaires were coded to guarantee anonymity. After filling out the questionnaire, the researcher presented information about the etiology, symptoms, prevention, and treatment of CTS to each respondent. The research team obtained verbal consent for participation and the final response to the questionnaire items was agreed upon to be equivalent to a final consent signature.

\section{Statistical analysis:}


Data were analyzed in SPSS software Version 25.0 (Armonk, New York: IBM Corp) using descriptive statistics (mean \pm standard deviation and percentage) and inferential statistics (comparing independent groups and analysis of variation). We used Kolmogorov-Smirnov to assess normal distribution of continuous variables; none of the variables followed a normal distribution and were analyzed using the Mann-Whitney U test, Kruskal-Wallis test, and Spearman's rank correlation test. A two-tailed $p$-value $<0.05$ was considered statistically significant.

\section{Results}

51 dentists completed the survey (56\% response rate). Most dentists who had not participated in the survey mentioned lack of time or interest as the primary reasons for opting out. 31 (60.8\%) respondents were female and 20 (39.2\%) were male. Almost one half of the participants were aged below 33 (54.9\%) years. The majority of participants $(70.6 \%)$ had job experience below 10 years. No statistically significant correlation was observed between age, and number of years of work experience and KAP scores. But there was significant correlation was observed between gender and Knowledge score (P-Value=0.04).

(Table 1)

Regarding medical history, about 29 (56.9\%) of participants experienced wrist pain in the past 6 months. The responses to the medical history of the questionnaire are summarized in Table 2.

Regarding Knowledge, the mean score of the knowledge of the questionnaire was $3.70 \pm 1.64$ with a minimum of 1 and a maximum of 9.24 (47.1\%) dentists had low knowledge, 26 (51\%) had average knowledge, and only one (1.9\%) had high knowledge regarding CTS. $47(92.2 \%)$ dentists were not familiar with the prevention and treatment, including the definitive treatment of this syndrome. (Table 3 )

Regarding Attitudes, the mean score of the attitudes part of the questionnaire was $10.92 \pm 3.18$ with a minimum of 1 and a maximum of 15.2 (3.9\%) respondents had low attitudes, 9 (17.6\%) had average attitudes, and $40(78.4 \%)$ had high attitudes toward CTS. The need for ergonomic enhancements was reported by $45(88.2 \%)$ dentists. Although $38(74.5 \%)$ dentists stated that CTS was not a serious disease; the same number of dentists believed that significant complications could arise from CTS. Most dentists $(72.5 \%)$ were aware of the high prevalence of this syndrome. (Table 4)

Regarding Practice, the mean score of the practice part of the questionnaire was $7.90 \pm 2.10$ with a minimum of zero and a maximum of 11.2 (3.9\%) participants scored low, 16 (31.3\%) scored average, and $33(64.7 \%)$ scored high on the practice part of the questionnaire. $36(70.6 \%)$ dentists were willing to try splinting for management of CTS, but most would forego surgery if they were diagnosed with CTS (86.3\%). 45(88.2\%) participants stated that they would refrain from working if they experienced symptoms of CTS. (Table 5)

Additionally, the spearman's correlation between knowledge, attitude, and practice showed significant correlation between attitude and practice among dentists with $p$ value=0.001. (Table 6) 


\section{Discussion}

Our results show that dentists in our study have low to average knowledge, high attitudes, and high practice scores regarding CTS. A study on 223 doctors regarding prevention of work-related musculoskeletal disorders (MSD) found that doctors had high knowledge, high attitudes, and average practice regarding this subject. ${ }^{[17]}$ Compared to dentists in our study, the higher knowledge scores of doctors are probably the result of their extensive education on MSD in medical school and in the form of continuing medical education (CME). Although both doctors and dentists have high attitudes, it seems that dentists' positive attitudes lead to practicing healthier principles.

Proper ergonomics are one of the most important factors in preventing CTS in dental health workers. ${ }^{[18]}$ The KAP of 250 dental professionals regarding ergonomics during routine dental procedures were assessed in another paper. ${ }^{[19]}$ The study showed that dental professionals, including undergraduates and private dental practitioners, had average KAP toward the subject. The author postulated that the slightly higher scores on practice compared to knowledge were due to informal training and self-learned optimal principles during practice. The same might be true for our study population. We found that dentists have high practice but low to average knowledge scores. We assume that while dentists had limited formal education on the subject of CTS in their dental school curriculum, they might have frequently experienced symptoms of CTS during their practice and had learned over time to adhere to techniques that alleviated the symptoms such as taking a break from work.

A survey of 55 dentists showed that participants lacked the positive attitudes and behavior to seek medical expert advice for prevention of work-related MSD in the initial stages. ${ }^{[20]}$ On the contrary, we found that dentists have high attitudes and practice scores regarding CTS and its prevention. Moreover, most dentists stated that they would visit their doctor the first time they experienced wrist pain. Hopefully, in the future, this will increase the number of diagnosed cases of CTS and help alleviate a common complaint among dental professionals and increase their work efficacy.

We found that the majority of dentists were aware of the fact that CTS is a preventable disease and that doing certain exercises of the hands for a few minutes every day can prevent CTS. A study of 169 workers at an electrical parts manufacturing company in South Korea evaluated the KAP of workers regarding MSD before and after a preventive exercise program and concluded that the educational program significantly increased the KAP of workers. ${ }^{[21]}$ Unfortunately, most participants in our study were not familiar with the appropriate exercises for the prevention of CTS and, therefore, were not exercising their hands regularly. Therefore, educational workshops or courses might prove useful, especially in increasing the knowledge about prevention of work-related MSD such as CTS among dentists.

As mentioned earlier, some patients will eventually require surgery for proper management of their symptoms; however, the majority of respondents stated that they would opt for conservative managements and forego surgery if they were diagnosed with CTS. Similarly, in a study of 77 patients with mild to moderately severe CTS, many chose not to be referred to a hand center for carpal tunnel 
release surgery. ${ }^{[22]}$ The reason why patients delay consideration of surgery might be the risk of unemployment. Studies show that patients normally return to work 2 to 7 weeks after carpal tunnel release surgery; ${ }^{[23,24]}$ while those with severe symptoms may take up to a year to recover. ${ }^{[13]}$

To conclude, CTS can be a life-changing and serious illness since $55 \%$ of ill-health retirements in dental practitioners are due to MSD. ${ }^{25]}$ The results of our study show that dentists have low to average knowledge, high attitudes, and high practice scores regarding CTS. We believe that the results of our study can be of importance in advancing the occupational health and productivity of dentists by providing a basis for a future main study.

Our paper has some drawbacks. First, the response rate was below average. Second, as this was a pilot study, the inferential statistics ( $p$-values) might not accurately represent the population of dentists in Shiraz, Iran. The future main study should be done with a larger sample size and with random samples from multiple cities to accurately represent the population of dentists in Iran.

\section{Conclusion}

Most dentists in this study had low to average knowledge, high attitudes, and high practice scores of the prevention and treatment of CTS.

\section{Declarations}

\section{Acknowledgments}

The authors would like to thank Shiraz University of Medical Sciences, Shiraz, Iran and also Center for Development of Clinical Research of Nemazee Hospital and Dr. Nasrin Shokrpour for editorial assistance.

\section{Conflict of interest}

The authors declare that they have no conflict of interests.

\section{Funding}

Non

Ethical Approvement: This manuscript was extracted from the MD thesis (NO. 17639) of Alireza Sadighi that was approved and granted by the vice-chancellor of research, Shiraz University of Medical Sciences, Shiraz, Iran with ethics code of IR.SUMS.MED.REC.1398.546.

\section{References}

1. Gupta A, Bhat M, Mohammed T, Bansal N, Gupta G. Ergonomics in dentistry.Int J Clin Pediatr Dent. 2014;7:30-4. 
2. Sartorio F, Vercelli S, Ferriero G, D'Angelo F, Migliario M, Franchignoni M. [Work-related musculoskeletal diseases in dental professionals. 1. Prevalence and risk factors].G Ital Med Lav Ergon. 2005;27:165-9.

3. Chammas M, Boretto J, Burmann LM, Ramos RM, Dos Santos Neto FC, Silva JB. Carpal tunnel syndrome - Part I (anatomy, physiology, etiology and diagnosis).Rev Bras Ortop. 2014;49:429-36.

4. Atroshi I, Gummesson C, Johnsson R, Ornstein E, Ranstam J, Rosén I. Prevalence of carpal tunnel syndrome in a general population.Jama. 1999;282:153-8.

5. Moosazadeh M, Asadi-Aliabadi M, Rostami F, Farshidi F, Karimi N. Prevalence of Carpal Tunnel Syndrome in Iran: A Systematic Review and Meta-analysis J Mazandaran Univ Med Sci. 2018;28:144-53.

6. Stevens JC, Smith BE, Weaver AL, Bosch EP, Deen HG, Jr., Wilkens JA. Symptoms of 100 patients with electromyographically verified carpal tunnel syndrome.Muscle Nerve. 1999;22:1448-56.

7. Harris-Adamson C, Eisen EA, Dale AM, Evanoff B, Hegmann KT, Thiese MS, et al. Personal and workplace psychosocial risk factors for carpal tunnel syndrome: a pooled study cohort.Occup Environ Med. 2013;70:529-37.

8. Maghsoudipour M, Moghimi S, Dehghaan F, Rahimpanah A. Association of occupational and nonoccupational risk factors with the prevalence of work related carpal tunnel syndrome.J Occup Rehabil. 2008;18:152-6.

9. Shiri R. Hypothyroidism and carpal tunnel syndrome: a meta-analysis.Muscle Nerve. 2014;50:879-83.

10. Simsir Atalay N, Sarsan A, Akkaya N, Yildiz N, Topuz O. The Impact of Disease Severity in Carpal Tunnel Syndrome on Grip Strength, Pinch Strength, Fine Motor Skill and Depression.J Phys Ther Sci. 2011;23:115-8.

11. Graham B. The value added by electrodiagnostic testing in the diagnosis of carpal tunnel syndrome.J Bone Joint Surg Am. 2008;90:2587-93.

12. Atroshi I, Flondell M, Hofer M, Ranstam J. Methylprednisolone injections for the carpal tunnel syndrome: a randomized, placebo-controlled trial.Ann Intern Med. 2013;159:309-17.

13. Wipperman J, Goerl K. Carpal Tunnel Syndrome: Diagnosis and Management.Am Fam Physician. 2016;94:993-9.

14. Haghighat A, Khosrawi S, Kelishadi A, Sajadieh S, Badrian H. Prevalence of clinical findings of carpal tunnel syndrome in Isfahanian dentists.Adv Biomed Res. 2012;1:13.

15. Kaewboonchoo O, Yamamoto H, Miyai N, Mirbod SM, Morioka I, Miyashita K. The Standardized Nordic Questionnaire Applied to Workers Exposed to Hand-Arm Vibration. 1998;40:218-22.

16. Kumar PM, Sahitya S, Penmetsa GS, Supraja S, Kengadaran S, Chaitanya A. Assessment of knowledge, attitude, and practice related to ergonomics among the students of three different dental schools in India: An original research.J Educ Health Promot. 2020;9:266.

17. Ephraim-Emmanuel BC, Ogbomade R, Idumesaro BN, Ugwoke I. Knowledge, Attitude and Practice of Preventing the Occurrence of Work-Related Musculoskeletal Disorders Among Doctors in University 
of Port-Harcourt Teaching Hospital.J Med Res Innov. 2019;3:e000161-e.

18. Sarkar PA, Shigli AL. Ergonomics in general dental practice. People's J Sci Res. 2012;5:56-60.

19. Kalghatgi S, Prasad KV, Chhabra KG, Deolia S, Chhabra C. Insights into ergonomics among dental professionals of a dental institute and private practitioners in hubli-dharwad twin cities, India.Saf Health Work. 2014;5:181-5.

20. Karibasappa G, Sujatha A, Rajeshwari K. Dentists' knowledge, attitude and behavior towards the dental ergonomics.IOSR J Dent Med Sci. 2014;13:86-9.

21. Koo J-W, Kim K-Y. The change of knowledge, attitude and practice on musculoskeletal diseases after exercise program in an electronic parts manufacturing company. Int Congr Ser. 2006;1294:143-6.

22. Burke FD, Storey PA, Wilgis EF. In justification of nonsurgical treatment for carpal tunnel syndrome.J Hand Surg Am. 2009;34:1360-1; author reply 1.

23. Bekkelund SI, Pierre-Jerome C, Torbergsen T, Ingebrigtsen T. Impact of occupational variables in carpal tunnel syndrome.Acta Neurol Scand. 2001;103:193-7.

24. Mallick A, Clarke M, Wilson S, Newey ML. Reducing the economic impact of carpal tunnel surgery.J Hand Surg Eur Vol. 2009;34:679-81.

25. Brown J, Burke FJ, Macdonald EB, Gilmour H, Hill KB, Morris AJ, et al. Dental practitioners and ill health retirement: causes, outcomes and re-employment.Br Dent J. 2010;209:E7.

\section{Tables}

Table 1. Comparisons of means of knowledge, attitudes, and practice scores in different demographic subgroups 


\begin{tabular}{|c|c|c|c|c|c|c|c|}
\hline Parameter & & $\begin{array}{l}\text { Knowledge } \\
\text { (Mean } \pm \\
\text { SD) }\end{array}$ & $\begin{array}{l}\text { P- } \\
\text { Value }\end{array}$ & $\begin{array}{l}\text { Attitudes } \\
\text { (Mean士 } \\
\text { SD) }\end{array}$ & $\begin{array}{l}\text { P- } \\
\text { Value }\end{array}$ & $\begin{array}{l}\text { Practice } \\
\text { (Mean } \pm \text { SD) }\end{array}$ & $\begin{array}{l}\text { P- } \\
\text { Value }\end{array}$ \\
\hline \multirow[t]{2}{*}{ Gender } & Female & $4 \pm 1.39$ & $0.04^{*}$ & $\begin{array}{l}10.77 \pm \\
3.68\end{array}$ & $0.70^{\star}$ & $7.97 \pm 2.33$ & $0.40^{*}$ \\
\hline & Male & $\begin{array}{l}3.25 \pm \\
1.92\end{array}$ & & $\begin{array}{l}11.15 \pm \\
2.28\end{array}$ & & $7.80 \pm 1.77$ & \\
\hline \multirow[t]{2}{*}{ Age (years) } & $\geq 33$ & $\begin{array}{l}3.89 \pm \\
1.71\end{array}$ & $0.45^{\star}$ & $\begin{array}{l}11.18 \pm \\
3.19\end{array}$ & $0.44^{*}$ & $8.04 \pm 1.90$ & $0.89^{*}$ \\
\hline & $<33$ & $\begin{array}{l}3.48 \pm \\
1.56\end{array}$ & & $\begin{array}{l}10.61 \pm \\
3.22\end{array}$ & & $7.74 \pm 2.38$ & \\
\hline \multirow[t]{3}{*}{$\begin{array}{l}\text { Work Experience } \\
\text { (years) }\end{array}$} & $\geq 10$ & $\begin{array}{l}3.83 \pm \\
1.72\end{array}$ & $0.38^{\dagger}$ & $\begin{array}{l}11.08 \pm \\
2.92\end{array}$ & $0.99^{\dagger}$ & $8.08 \pm 1.90$ & $0.35^{\dagger}$ \\
\hline & $\begin{array}{l}11 \text { to } \\
20\end{array}$ & $\begin{array}{l}3.70 \pm \\
1.64\end{array}$ & & $\begin{array}{l}10.60 \pm \\
3.89\end{array}$ & & $7.70 \pm 2.98$ & \\
\hline & $<21$ & $\begin{array}{l}2.80 \pm \\
0.84\end{array}$ & & $\begin{array}{l}10.40 \pm \\
4.10\end{array}$ & & $7.00 \pm 1.58$ & \\
\hline
\end{tabular}

* Mann-Whitney U test

† Kruskal-Wallis test

Table 2. Results of the medical history section of the questionnaire 


\section{Question}

\section{Choices}

Number of $n(\%)$ times

1. Have you experienced wrist pain in the past 6 months? If yes, Yes specify how many times.

\begin{tabular}{lll} 
Yes & 1 & $\begin{array}{l}6 \\
(11.8 \%)\end{array}$ \\
& & 14 \\
& 2 & $(27.5 \%)$ \\
& 3 & $(5.9 \%)$ \\
& & 4 \\
& & $(7.8 \%)$ \\
& 4 & 2 \\
& & $(3.9 \%)$ \\
& 5 & 29 \\
& & $(56.9 \%)$ \\
& Total & 22 \\
& & $(43.1 \%)$ \\
\hline No & &
\end{tabular}

2. Have you ever been absent from work due to wrist pain? If yes, Yes specify how many times.

$\begin{array}{lll}\text { Yes } & 1 & \begin{array}{l}3 \\ (5.9 \%)\end{array} \\ & & 2 \\ & 2 & (3.9 \%) \\ & & 5 \\ & \text { Total } & (9.8 \%) \\ & & 46 \\ \text { No } & & (90.2 \%)\end{array}$

3. Have you ever left work early due to wrist pain?

$\begin{array}{lll}\text { Yes } & - & 3 \\ & & (5.9 \%) \\ \text { No } & - & 48 \\ & & (94.1 \%) \\ \text { Yes } & - & 3 \\ & & (5.9 \%) \\ \text { No } & - & 48 \\ & & (94.1 \%)\end{array}$

5. Do you suffer from diabetes or other endocrine diseases?

$\begin{array}{lll}\text { Yes } & - & 5 \\ & & (9.8 \%) \\ \text { No } & - & 46 \\ & & (90.2 \%)\end{array}$

6. Do you suffer from any rheumatologic disease?

$\begin{array}{lll}\text { Yes } & 1(2 \%) \\ \text { No } & - & 50 \\ & - & (98 \%)\end{array}$




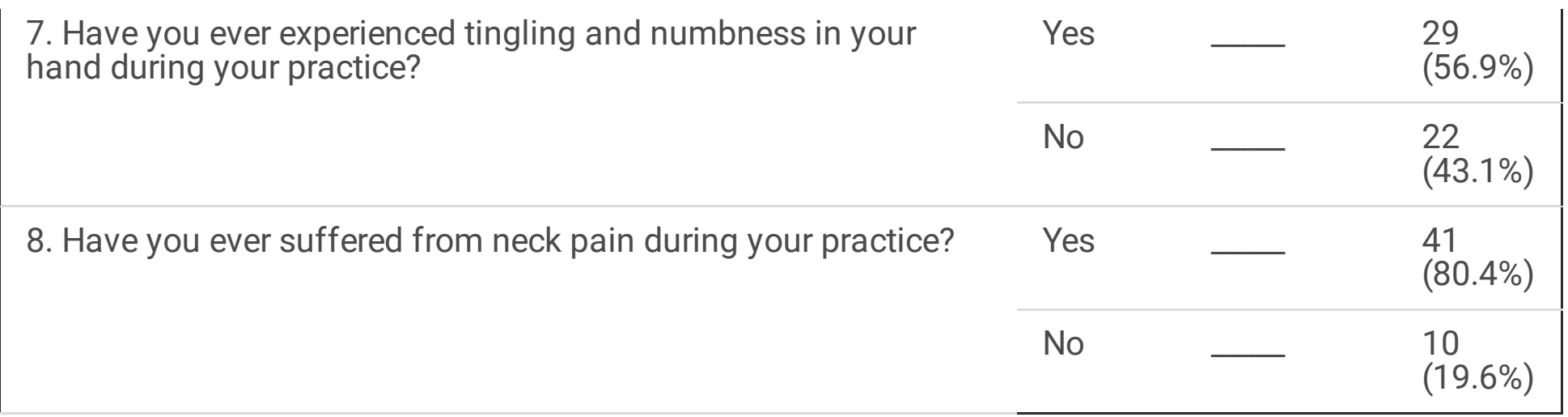

Table 3. Results of the knowledge part of the questionnaire 
Question

1. Are pain, numbness, and tingling in the thumb, index, and middle fingers symptoms of CTS?
Answered

Correctly (YES)

Incorrectly (NO)

Incorrectly (YES) 2. Are pain, numbness,
symptoms of CTS?

Correctly (NO)

3. Which nerve is affected in CTS?

Correctly (Median Nerve) $1(2 \%)$

Incorrectly (Ulnar /

Radial Nerve)

4. In which region of the upper extremity is the nerve affected?

5. Does smoking have an association with CTS?

Correctly (Wrist) 23

$(98 \%)$

Incorrectly (Neck /

Elbow)

Correctly (YES)

Incorrectly (NO)

6. Is diabetes mellitus associated with CTS?

Correctly (YES)

19

Incorrectly (NO)

32

$(67.2 \%)$

7. Does obesity have an association with CTS?

Correctly (YES)

24

$(47.1 \%)$

Incorrectly (NO)

27

$(52.9 \%)$

8. Is repetitive hand use the cause of CTS?

Correctly (YES)

Incorrectly (NO)

9. Do you know how to prevent CTS?

YES

4 $(7.8 \%)$

NO

10. Are you familiar with the treatment options of CTS?

YES 4 $(7.8 \%)$ 
11. What is the gold standard for diagnosis of CTS?

Correctly (EMG studies)

5

$(9.8 \%)$

Incorrectly (Blood test/

46

Wrist MRI / PE)

12. Is surgery the definitive treatment for CTS?

\begin{tabular}{ll} 
YES & 4 \\
& $(7.8 \%)$ \\
\hline NO & 47 \\
& $(92.2 \%)$ \\
\hline
\end{tabular}

EMG: Electromyography MRI: Magnetic resonance imaging, PE, Physical examination

Table 4. Results of the attitudes part of the questionnaire 


\begin{tabular}{|c|c|c|}
\hline Questions & Answere & $\mathrm{n}(\%)$ \\
\hline \multirow[t]{2}{*}{$\begin{array}{l}\text { 1. Can answers to the questions in the knowledge part help you improve } \\
\text { your work conditions? }\end{array}$} & YES & $\begin{array}{l}38 \\
(74.5 \%)\end{array}$ \\
\hline & NO & $\begin{array}{l}13 \\
(25.5 \%)\end{array}$ \\
\hline \multirow[t]{2}{*}{ 2. Are you interested in knowing more about CTS? } & YES & $\begin{array}{l}47 \\
(92.2 \%)\end{array}$ \\
\hline & NO & $\begin{array}{l}4 \\
(7.8 \%)\end{array}$ \\
\hline \multirow[t]{2}{*}{ 3. Can CTS affect your work status? } & YES & $\begin{array}{l}42 \\
(82.4 \%)\end{array}$ \\
\hline & NO & $\begin{array}{l}9 \\
(17.6 \%)\end{array}$ \\
\hline \multirow[t]{2}{*}{ 4. Are the complications of CTS significant for you? } & YES & $\begin{array}{l}38 \\
(74.5 \%)\end{array}$ \\
\hline & NO & $\begin{array}{l}13 \\
(25.5 \%)\end{array}$ \\
\hline \multirow[t]{2}{*}{ 5. Do you believe CTS has a low prevalence? } & NO & $\begin{array}{l}37 \\
(72.5 \%)\end{array}$ \\
\hline & YES & $\begin{array}{l}14 \\
(27.5 \%)\end{array}$ \\
\hline \multirow[t]{2}{*}{$\begin{array}{l}\text { 6. Do you believe certain simple exercises for a few minutes every day can } \\
\text { prevent CTS? }\end{array}$} & YES & $\begin{array}{l}43 \\
(84.3 \%)\end{array}$ \\
\hline & NO & 8 \\
\hline \multirow[t]{2}{*}{$\begin{array}{l}\text { 7. Would you be interested in sharing your knowledge of CTS with your } \\
\text { colleagues? }\end{array}$} & YES & $\begin{array}{l}41 \\
(80.4 \%)\end{array}$ \\
\hline & NO & $\begin{array}{l}10 \\
(19.6 \%)\end{array}$ \\
\hline \multirow[t]{2}{*}{ 8. Would you visit your doctor if you had symptoms of CTS? } & YES & $\begin{array}{l}44 \\
(86.3 \%)\end{array}$ \\
\hline & NO & $\begin{array}{l}7 \\
(13.7 \%)\end{array}$ \\
\hline \multirow[t]{2}{*}{ 9. Do you feel the need for ergonomic enhancements in your workplace? } & YES & $\begin{array}{l}45 \\
(88.2 \%)\end{array}$ \\
\hline & NO & $\begin{array}{l}6 \\
(11.8 \%)\end{array}$ \\
\hline 10. Do you think CTS is a preventable disease? & YES & $\begin{array}{l}43 \\
(84.3 \%)\end{array}$ \\
\hline
\end{tabular}




\begin{tabular}{|c|c|c|}
\hline & NO & $\begin{array}{l}8 \\
(15.7 \%)\end{array}$ \\
\hline \multirow[t]{2}{*}{ 11. Do you think CTS can be cured? } & YES & $\begin{array}{l}28 \\
(54.9 \%)\end{array}$ \\
\hline & NO & $\begin{array}{l}23 \\
(45.1 \%)\end{array}$ \\
\hline \multirow[t]{2}{*}{ 12. Can CTS be managed by splinting? } & $\begin{array}{l}\text { Correctly } \\
\text { (YES) }\end{array}$ & $\begin{array}{l}35 \\
(68.6 \%)\end{array}$ \\
\hline & $\begin{array}{l}\text { Incorrectly } \\
\text { (NO) }\end{array}$ & $\begin{array}{l}16 \\
(31.4 \%)\end{array}$ \\
\hline \multirow[t]{2}{*}{ 13. Can regional corticosteroid injections be used in management of CTS? } & $\begin{array}{l}\text { Correctly } \\
\text { (YES) }\end{array}$ & $\begin{array}{l}35 \\
(68.6 \%)\end{array}$ \\
\hline & $\begin{array}{l}\text { Incorrectly } \\
\text { (NO) }\end{array}$ & $\begin{array}{l}16 \\
(31.4 \%)\end{array}$ \\
\hline \multirow[t]{2}{*}{ 14. Can nerve conduction velocity testing identify the severity of CTS? } & $\begin{array}{l}\text { Correctly } \\
\text { (YES) }\end{array}$ & $\begin{array}{l}28 \\
(54.9 \%)\end{array}$ \\
\hline & $\begin{array}{l}\text { Incorrectly } \\
\text { (NO) }\end{array}$ & $\begin{array}{l}23 \\
(45.1 \%)\end{array}$ \\
\hline 15. Is CTS a serious disease? & YES & $\begin{array}{l}13 \\
(25.5 \%)\end{array}$ \\
\hline
\end{tabular}

Table 5. Results of the practice part of the questionnaire 
Statement

1. I will take a break from work if I experienced wrist pain

2. I will try to gain more insight into CTS 


\begin{tabular}{|c|c|c|}
\hline & NO & $\begin{array}{l}8 \\
(15.7 \%)\end{array}$ \\
\hline \multirow[t]{2}{*}{$\begin{array}{l}\text { 11. I will change my work-hours so I can rest for a few minutes for every hour } \\
\text { of work }\end{array}$} & YES & $\begin{array}{l}36 \\
(70.6 \%)\end{array}$ \\
\hline & NO & $\begin{array}{l}15 \\
(29.4 \%)\end{array}$ \\
\hline \multirow[t]{2}{*}{ 12. I will refrain from working if I had symptoms of CTS } & YES & $\begin{array}{l}45 \\
(88.2 \%)\end{array}$ \\
\hline & NO & $\begin{array}{l}6 \\
(11.8 \%)\end{array}$ \\
\hline
\end{tabular}

Table 6: Spearman's correlation among knowledge, Attitude, and practice among dentists.

\begin{tabular}{|llll|}
\hline Parameter & Knowledge & Attitude & Practice \\
\hline Knowledge & - & 0.21 & 0.81 \\
\hline Attitude & 0.21 & - & $\mathbf{0 . 0 0 1}$ \\
\hline Practice & 0.81 & $\mathbf{0 . 0 0 1}$ & - \\
\hline
\end{tabular}

